\title{
Theoretical Comparison of the Effects of Different Traffic Conditions on Urban Road Traffic Noise
}

\author{
Mohammad Maghrour Zefreh (iD) and Adam Torok (iD) \\ Budapest University of Technology and Economics, Department of Transport Technology and Economics, \\ Stoczek St. 2, Building ST, 1111 Budapest, Hungary \\ Correspondence should be addressed to Adam Torok; torok.adam@mail.bme.hu
}

Received 10 May 2018; Revised 16 August 2018; Accepted 25 September 2018; Published 15 October 2018

Guest Editor: Vladislav Zitricky

Copyright (C) 2018 Mohammad Maghrour Zefreh and Adam Torok. This is an open access article distributed under the Creative Commons Attribution License, which permits unrestricted use, distribution, and reproduction in any medium, provided the original work is properly cited.

\begin{abstract}
Road traffic noise is one of the most relevant sources in the environmental noise pollution of the urban areas where dynamics of the traffic flow are much more complicated than uninterrupted traffic flows. It is evident that different traffic conditions would play the role in the urban traffic flow considering the dynamic nature of the traffic flow on one hand and presence of traffic lights, roundabouts, etc. on the other hand. The main aim of the current paper is to investigate the effect of different traffic conditions on urban road traffic noise. To do so, different traffic conditions have been theoretically generated by the Monte Carlo Simulation technique following the distribution of traffic speed in the urban roads. The "ASJ RTN-Model" has been considered as a base road traffic noise prediction model which would deal with different traffic conditions including steady and nonsteady traffic flow that would cover the urban traffic flow conditions properly. Having generated the vehicles speeds in different traffic conditions, the emitted noise $\left(L_{W A}\right)$ and subsequently the noise level at receiver $\left(L_{A}\right)$ were estimated by "ASJ RTN-Model." Having estimated $L_{W A}$ and $L_{A}$ for each and every vehicle in each traffic condition and taking the concept of transient noise into account, the single event sound exposure levels (SEL) in different traffic conditions are calculated and compared to each other. The results showed that decelerated traffic flow had the lowest contribution, compared to congestion, accelerated flow, free flow, oversaturated congestion, and undersaturated flow by $16 \%, 14 \%, 12 \%, 12 \%$, and 10\%, respectively. Moreover, the distribution of emitted noise and noise level at receiver were compared in different traffic conditions. The results showed that traffic congestion had considerably the maximum peak compared to other traffic conditions which would highlight the importance of the range of generated noise in different traffic conditions.
\end{abstract}

\section{Introduction}

Highly industrialized living style of modern societies has produced a dramatic impact on the environment [1]. Nowadays, the environment noise and emission [2] have become a worldwide problem and the environmental impact control is one of the most important problems in the urban areas [3]. It is reasonable to affirm that, in urban areas, road traffic noise is the most relevant source [4] since airports are usually placed outside the downtowns and railways are usually designed to move out from the center of the cities [5] and rarely cross the residential districts [6]. Furthermore, in urban areas, the concentration of both road networks and city dwellers makes of traffic flow the main culprit of noise annoyance, which has to be precisely estimated and treated through relevant road traffic mitigation [7]. Although the road noise is not usually loud enough to cause hearing problems, continuous exposure to unacceptable noise levels can create the adverse effects on health [8]. Moreover, environmental noise exposure is associated with annoyance $[9,10]$, sleep disturbance [11], cognitive ability in schoolchildren [12], and health impacts, especially cardiovascular conditions [13]. Exposure to environmental noise is pervasive and increasing in terms of road traffic noise and the reduction of the night-time quiet period [14]. Trafficrelated noise is one of the major environmental impacts of roadways [15] and is said to account for over 1 million healthy years of life lost annually to ill health and may lead to a disease burden that is second only in magnitude to that from air pollution [16]. According to the WHO, the environment noise costs societies $0.2 \%-2.0 \%$ of the gross domestic product [17]. 
Therefore, urban road traffic emission and noise should be included in the economic evaluation of an urban road traffic policy [18] since different traffic conditions, as consequence of these policies, might have a considerable contribution in the urban road traffic noise emission which would have a significant impact on the gross domestic product of the societies. Noise prediction is one of the vital tools for city planners for noise abatement and control [19]. Traffic management can be a very effective policy to fight against urban traffic noise $[20,21]$ which is increasingly implemented in European [22] noise reduction projects. By taking a wide look at the literature, mostly, noise impacts of traffic management policies have been measured/investigated by conducting the on-field studies [23]. The current research instead seeks to provide a theoretical comparison environment in which the average impact of different traffic conditions on road traffic noise emission would be compared. Generally, the estimation of the noise emissions generated by road traffic requires both a noise emission model that captures the impact of vehicle kinematics, namely, speed and acceleration, on sound power levels, and an accurate estimation of the kinematic variables of interest in the area under study [24]. There are various models developed recently in order to evaluate the road traffic noise emissions. For instance, the Federal Highway Administration Traffic Noise Model (FHWA TNM) of USA [25] predicts the hourly equivalent sound level of the $i^{\text {th }}$ class of vehicles based on the reference energy mean emission level of the $i^{\text {th }}$ class of vehicles which refers to the maximum sound level emitted by a vehicle pass-by at a reference distance of 15 (m) through a series of adjustments as follows.

$$
L_{e q}(h)_{i}=\left(\overline{L_{0}}\right)_{E i}+\Delta_{f(i)}+\Delta_{d}+\Delta_{l}+\Delta_{s}
$$

where

$$
\begin{aligned}
& L_{e q}(h)_{i} \text { is hourly equivalent sound level }(d B(A)) \\
& \left(\overline{L_{0}}\right)_{E i} \text { is reference energy mean emission level } \\
& (d B(A)) \\
& \Delta_{f(i)} \text { is traffic flow adjustment } \\
& \Delta_{d} \text { is distance adjustment } \\
& \Delta_{l} \text { is length of the roadway adjustment } \\
& \Delta_{s} \text { is shielding adjustment }
\end{aligned}
$$

The CoRTN (Calculation of Road Traffic Noise) model of the United Kingdom estimates the A-weighted sound pressure level that is exceeded for $10 \%$ of the measurement period at a reference distance of $10(\mathrm{~m})$ away from the nearside carriageway edge as follows [26].

$$
\begin{aligned}
L_{10}= & 42.2+10 \log _{10} q+\Delta_{f}+\Delta_{g}+\Delta_{p}+\Delta_{d}+\Delta_{s} \\
& +\Delta_{a}+\Delta_{r}
\end{aligned}
$$

where

$L_{10}$ is A-weighted sound pressure level that is exceeded for $10 \%$ of the measurement period $(\mathrm{dB}(\mathrm{A}))$ $q$ is total hourly flow (veh/hr) calculated at a reference distance of $10(\mathrm{~m})$ at an average traffic speed of 75 $(\mathrm{km} / \mathrm{h})$

$\Delta_{f}$ is traffic flow adjustment

$\Delta_{g}$ is gradient adjustment

$\Delta_{p}$ is pavement type adjustment

$\Delta_{d}$ is distance adjustment

$\Delta_{s}$ is shielding adjustment

$\Delta_{a}$ is angle of view adjustment

$\Delta_{r}$ is reflection adjustment

The HARMONOISE (Harmonised Accurate and Reliable Methods for the EU Directive on the Assessment and Management of Environmental Noise) model [27] of the European Union is defined based on two sound power values for different vehicle categories as follows.

$$
\begin{aligned}
& L_{W R}(f)=a_{R}(f)+b_{R}(f) \log \left(\frac{V}{V_{r e f}}\right) \\
& L_{W P}(f)=a_{P}(f)+b_{P}(f) \log \left(\frac{V-V_{r e f}}{V_{\text {ref }}}\right)
\end{aligned}
$$

where

$L_{W R}(f)$ is rolling noise generated by tire-road interaction and aerodynamic drag $(\mathrm{dB}(\mathrm{A}))$

$L_{W P}(f)$ is propulsion noise generated by the powertrain and the exhaust $(\mathrm{dB}(\mathrm{A}))$

$V_{\text {ref }}$ is $70(\mathrm{~km} / \mathrm{h})$

$a_{R}(f), b_{R}(f), a_{P}(f)$, and $b_{P}(f)$ are given coefficients in $1 / 3^{r d}$ octave bands in frequency range 25 to $10 \mathrm{kHz}$

The ASJ RTN-Model (Acoustical Society of Japan Road Traffic Noise prediction model) considers a single vehicle as an omnidirectional point source passing along the road under consideration and predicts the noise emitted by each vehicle in different categories as a function of the vehicle speed in different traffic conditions (steady and nonsteady traffic flow, acceleration, and deceleration running condition) as follows [28].

$$
L_{W A}=a+b \log (V)+c
$$

where

$L_{W A}$ is A-weighted sound power level (noise emitted by each vehicle) $(\mathrm{dB}(\mathrm{A}))$

$V$ is vehicle speed $(\mathrm{km} / \mathrm{h})$

$a$ and $b$ are regression coefficients

$c$ is correction term for road conditions (pavement type and road gradient)

Furthermore, noise propagation from the $i^{\text {th }}$ source position to the prediction point will be predicted as follows.

$$
L_{A, i}=L_{W A, i}-8-20 \log r_{i}+\Delta L_{c o r, i}
$$

where 
$L_{A, i}$ is A-weighted sound pressure level (noise level at receiver) ( $\mathrm{dB}(\mathrm{A}))$

$r_{i}$ is direct distance from the $i^{\text {th }}$ source position to the prediction point $(\mathrm{m})$

$\Delta L_{c o r, i}$ is correction for diffraction, ground effect, and atmospheric absorption $(\mathrm{dB}(\mathrm{A}))$

The main aim of the current research is to investigate the contribution of different traffic conditions in noise emission of the urban road traffic flow by preparing a theoretical comparison in which each traffic condition would generate road traffic noise independently. In the current study, different traffic conditions have been represented by the distribution of traffic speed in that traffic condition obtained by on-field data collection. It is worth to mention that the role of speed distribution on road traffic emission [29] and noise has been investigated in the literature. For instance, the effects of speed distributions on the Harmonoise model predictions have been investigated by [30]. They assumed when traffic is freely moving the speed distribution of a given category of vehicle approximates to a normal distribution. It is a very general assumption and they did not consider the situation in which the traffic flow freely moves but it is close to the capacity. They examined the errors in noise prediction which would result if the mean speed was used for prediction purposes rather than the actual speed distribution. They pointed out that it is likely that the assumptions concerning a normal distribution are not so robust due to the potential periods of congested traffic so that the estimates of standard deviation could be misleading. Also, due to the lack of data at the individual level, they have roughly assumed some other distributions for the other simple traffic conditions. The main difference of this paper with our paper is that we have investigated the effect of different traffic conditions based on the actual (fitted to empirical data) speed distributions adapted to the empirical traffic speed data obtained by the on-site traffic data collection in the city of Budapest, Hungary. In 2013, Iannone et al. [31] studied the influence of speed distribution on road traffic noise prediction. In their study, they investigated the effect of speed distribution (different speed distributions were simulated following the same average speed, $70(\mathrm{~km} / \mathrm{h})$ and standard deviation, $10(\mathrm{~km} / \mathrm{h}))$ on road traffic noise prediction using the "Micro to Macro" approach that adopts the single vehicle noise emission. The random extraction of the speed allows running the model also when single vehicle speed data are not available. In the current paper, the effects of different traffic conditions (different speed distributions and different speed specifications obtained by empirical data collection in city of Budapest) on urban road traffic noise were theoretically compared to each other using the Japanese reference noise model which is calibrated for different traffic conditions.

A majority of the researches in dynamic road traffic noise prediction topic considered the microscopic traffic flow characteristics (speed, acceleration, etc. of each and every single vehicles) instead of the macroscopic traffic flow characteristics (average parameters of the entire traffic flow) as the main element of the road traffic dynamics for noise prediction $[24,32,33]$. In the current paper, different

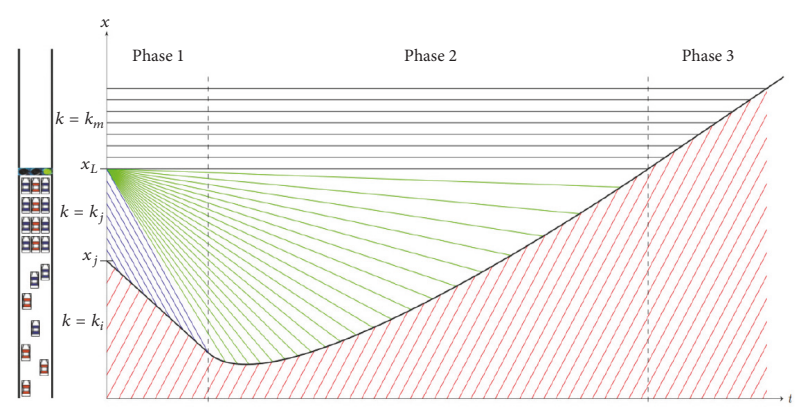

FIGURE 1: Characteristic diagram for traffic moving at a traffic light.

traffic conditions have been theoretically generated based on the distribution of vehicles speed on that traffic condition. Furthermore, the reference road traffic noise model of Japan, the ASJ RTN-Model, has been selected as a base road traffic noise prediction model due to the fact that it is calibrated for both steady and nonsteady traffic flow (adapted for urban condition). Moreover, this model is also calibrated for acceleration and deceleration running conditions which would be appropriate in predicting the road traffic noise emissions close to the intersections. Apart from these, the base of the model is directly dependent on the speed of vehicles which is the considered characteristic of different traffic conditions in this research.

The rest of the paper is organized as follows. In Section 2, at first, different traffic conditions have been theoretically generated according to the distribution of vehicles speed in different traffic conditions and then the generated road traffic noise in each traffic condition is estimated using the ASJ RTN-Model. The estimated road traffic noises in different traffic conditions have been compared and discussed in terms of magnitude and continuity in Section 3. Finally, the paper is concluded in Section 4.

\section{Methodology}

The main aim of the current research is to compare the effects of different traffic conditions on urban road traffic noise. To do so, a field measurement campaign (manual video recording) has been done by the Stipendium Hungaricum (2016-2017/MSc) transportation engineering students in the two-lane Villnyi street and Karolina street intersection in Budapest, XI district, Hungary, during the entire day. Six different traffic conditions (scenarios) have been defined based on the recorded videos. The defined scenarios are theoretically explained here using a theoretical representation of a characteristic diagram for traffic moving at a traffic light when it turns to green as shown in Figure 1. The condition in which the traffic congestion would not be disappeared in a cycle (exceeds the capacity) is considered as oversaturated congestion. This is the region $x_{j} \leq x<x_{L}$ in Figure 1 where density is close to Jam density $\left(k_{j}\right)$. The undersaturated flow is considered when the traffic is close to the capacity (and will be discharged in a cycle) in the region $x<x_{j}$ where traffic is flowing with the density lower than optimal density $\left(k_{i}<k_{m}\right)$, as the flow is not unimpeded. The free 
TABLE 1: Specifications of traffic speed in different traffic conditions.

\begin{tabular}{|c|c|c|c|c|c|}
\hline Traffic condition & Fitted speed distribution & $\begin{array}{c}\text { Minimum } \\
\text { speed }(\mathrm{km} / \mathrm{h})\end{array}$ & $\begin{array}{c}\text { Maximum } \\
\text { speed }(\mathrm{km} / \mathrm{h})\end{array}$ & $\begin{array}{l}\text { Average speed } \\
(\mathrm{km} / \mathrm{h})\end{array}$ & $\begin{array}{c}\text { SD of speed } \\
(\mathrm{km} / \mathrm{h})\end{array}$ \\
\hline Over-saturated congestion & Exponential distribution & 1 & 15.5 & 10.37 & 2.74 \\
\hline Under saturated flow & Normal distribution & 25 & 55 & 38.14 & 6.46 \\
\hline Free flow & Log-normal distribution & 35 & 55 & 47.18 & 5.5 \\
\hline Congestion & Gamma distribution & 10 & 25 & 14.53 & 3.91 \\
\hline Accelerated flow & Beta distribution & 1 & 45 & 27.41 & 13.15 \\
\hline Decelerated flow & Chi-square distribution & 1 & 35 & 18.76 & 11.82 \\
\hline
\end{tabular}

flow traffic is considered when there are a few numbers of vehicles in the street (much lower than the capacity) in the region $x<x_{j}$ where traffic is flowing with the density lower than optimal density $\left(k_{i}<k_{m}\right)$, as the flow is not unimpeded. The deceleration process is considered in the condition where traffic flow is getting closer to $x_{j}$ (where the shockwave, black curve, travels backward through the traffic in phase 1 shown in Figure 1). When the traffic light turns green, vehicles are able to leave the light entirely unimpeded, so the density would be equal to optimal density $\left(k=k_{m}\right)$ and obviously flow would be in its maximum. This condition is considered as the acceleration process in which the shockwave slows down and starts to move back towards the traffic light (phase 2 ). The condition in which traffic light turns to green but the intersection is not completely empty yet is considered as congestion.

Having collected the speed of vehicles in different traffic conditions, the distribution of speed in these traffic conditions was estimated by the Maximum Likelihood Estimation method as follows.

$$
L(\theta)=\prod_{i=1}^{n} f\left(x_{i} \mid \theta\right)
$$

where

$$
\begin{aligned}
& x_{i} \text { is observed traffic speed }(\mathrm{km} / \mathrm{h}) \\
& f(\cdot \mid \theta) \text { is density function of the candidate paramet- } \\
& \text { ric distribution }
\end{aligned}
$$

Having estimated different candidate parametric distributions for traffic speed in different traffic conditions based on (7), the candidate distributions were compared to each other by three goodness-of-fit tests (Kolmogorov-Smirnov, Cramer-von-Mises, and Anderson-Darling) in order to find best-fitted speed distribution in each traffic condition as follows.

$$
\begin{gathered}
K S: \sup \left|F_{n}(x)-F(x)\right| \\
C v M: \int_{-\infty}^{\infty}\left(F_{n}(x)-F(x)\right)^{2} d x \\
A D: n \int_{-\infty}^{\infty} \frac{\left(F_{n}(x)-F(x)\right)^{2}}{F(x)(1-F(x))} d x
\end{gathered}
$$

where
$F_{n}$ is empirical cumulative distribution function of the vehicles speeds

$F_{x}$ is fitted theoretical parametric distribution

Apart from these three goodness-of-fit tests, two classical penalized criteria (Akaike and Bayesian information criteria) based on the log-likelihood were further considered to tackle the overfitting problems as follows.

$$
\begin{gathered}
A I C: 2 k-2 \ln (\widehat{L}) \\
B I C: \ln (n) k-2 \ln (\widehat{L})
\end{gathered}
$$

where

$k$ is number of estimated parameters in the model

$\widehat{L}$ is maximum value of the likelihood function for the model

$n$ is number of observations

The best-fitted distributions to the traffic speed in different traffic conditions along with the statistical specifications of the traffic speed in different traffic conditions are shown in Table 1 .

Taking Table 1 into account, one would find out that the fitted distributions are all unimodal distributions. It should be highlighted that, in the current study, a homogeneous traffic flow (passenger cars) has been considered in both data collection and simulation phases. Therefore, singlemode distributions (fitted unimodal distribution) have been considered to simulate traffic speed in different traffic conditions since the literature suggests considering bimodal and multimodal distributions while there is a heterogeneity in traffic flow [34]. There is a lot of research that has examined distribution models for motorized vehicle speed data in uncongested traffic condition. On one hand, $[35,36]$ found that, for lightly trafficked two-lane roads where most vehicles are traveling freely, car speeds measured in time are approximately normally distributed. Also, Minh et al. mentioned that speed distribution would follow normal distribution on the urban roads, 2005 [37]. From the other hand, log-normal distribution has been considered for modeling speed data [38, 39] since it offers the advantage that the same functional form is retained when the time speed distribution is transformed into a space-speed distribution and avoids the theoretical difficulty of the negative speeds given by the infinite tails of 


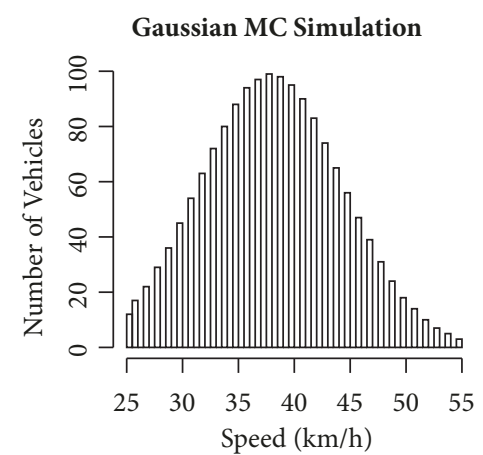

Exponential MC Simulation

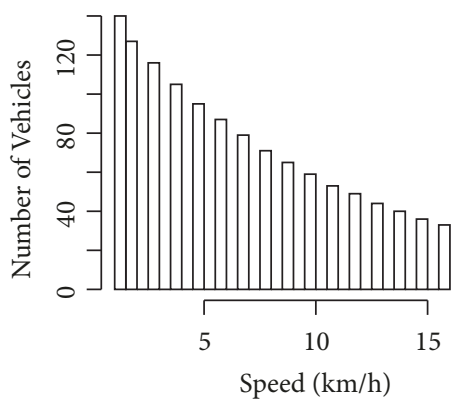

Log-normal MC Simulation

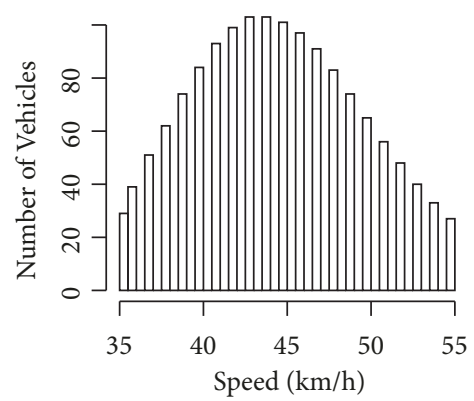

Beta MC Simulation

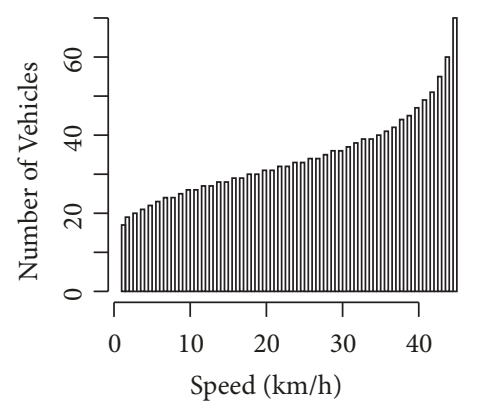

Gamma MC Simulation

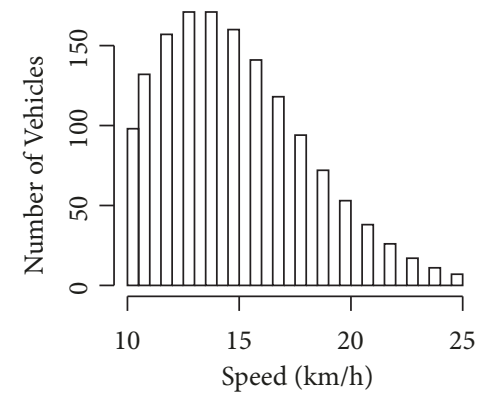

Chi-square MC Simulation

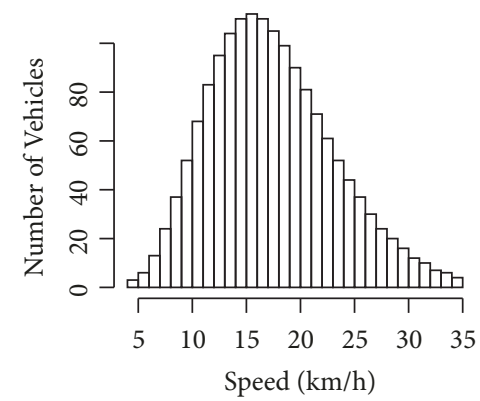

FIgURE 2: Random speed generation by Monte Carlo (MC) Simulation.

the normal distribution. In regard to log-normal distribution, Haight and Mosher [40] considered log-normal distribution since the speed data could be well represented by log-normal distribution in that study. Furthermore, [41, 42] suggested considering log-normal speed distribution for traffic speed simulation. Considering the fundamental relationship of the traffic flow, in the current study, the log-normal distribution is fitted better to the collected traffic speed in free flow condition (the condition in which much lower vehicles than the capacity were available in the roadway) and normal distribution is fitted better to the traffic speed in undersaturated flow condition (close to capacity condition).

2.1. Simulation of Different Traffic Conditions. In order to study the effect of different traffic conditions on road traffic noise emission, these traffic conditions were theoretically simulated by Monte Carlo (MC) simulation technique using the specifications of traffic speed in different traffic conditions shown in Table 1. It should be highlighted that the number of vehicles was considered to be constant (1600 vehicles) in each traffic condition in order to release the effect of traffic flow on further road traffic noise estimation. The randomly generated vehicles speeds which would represent the speed of vehicles in different traffic conditions are shown in Figure 2.

2.2. Road Traffic Noise Estimation. Having simulated the traffic speed in different traffic conditions theoretically, the A-weighted sound power level, $L_{W A}$, which would represent noise emitted by each single vehicle was calculated based on (5) in which the entire traffic flow has been considered to be in the same classification (passenger cars) with the same engine rotational speed, the same engine load, the same

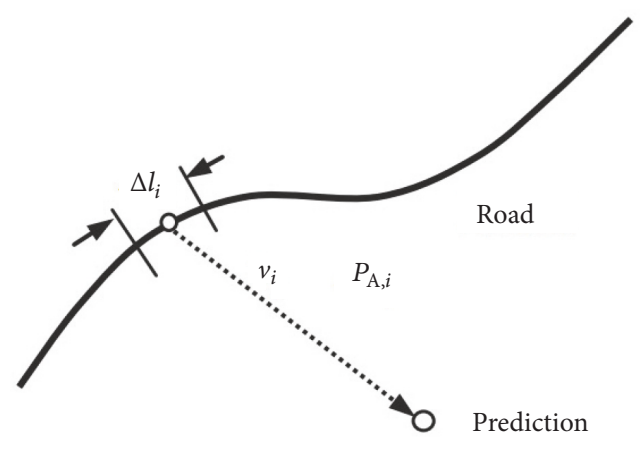

FIGURE 3: Sound propagation from a sound source to a prediction point [28].

road pavement type, and the same road geometry in order to release the effect of determinants other than traffic condition on emission estimation.

The calculated $L_{W A}$ for each vehicle is further considered as the basis of sound propagation as suggested by [28] and shown schematically in Figure 3 in which $P_{A, i}$ is the Aweighted sound power, $\Delta l_{i}(m)$ is the length of theoretical road, and $v_{i}(\mathrm{~km} / \mathrm{h})$ is the running speed of vehicle.

Hence, the A-weighted sound pressure level, $L_{A}$, which would represent the noise level at receiver was calculated based on (6) considering the same distance from the source position to the prediction point $(20(\mathrm{~m}))$, and the same $\Delta L_{c o r, i}$ for the entire traffic conditions in order to release the effect of determinants other than traffic condition on sound propagation estimation. Moreover, it is worth to mention that a representative point (fixed point source) has been set 
TABLE 2: Theoretical upper and lower boundaries of traffic noise in different traffic conditions.

\begin{tabular}{lcccc}
\hline Traffic condition & Min & Max & Min & Max \\
$(d B(A))$ & $L_{W A}(d B(A))$ & 82 & 94.04 \\
Over-saturated congestion & 47.97 & 60.02 & 88.33 & 98.61 \\
Under saturated flow & 54.31 & 64.59 & 92.72 & 98.61 \\
Free flow & 58.7 & 64.59 & 92 & 95.97 \\
Congestion & 57.97 & 61.95 & 82 & 98.53 \\
Accelerated flow & 47.97 & 64.51 & 76.4 & 92.72 \\
Decelerated flow & 42.38 & 58.7 & $L_{W A}$ & \\
\hline
\end{tabular}

at the center point of the theoretical road section. In this case, the A-weighted sound power level $L_{W A}$ emitted from the source (the vehicle) is set, and the A-weighted sound pressure level at the prediction point is calculated by applying a formula based on geometrical spreading (inverse-square law). It should be underlined that setting the fixed point source at the center point of the theoretical road section might result in an overestimation of the noise level. In the current research, this overestimation has been neglected due to the fact that a theoretical comparison platform has been provided such that the effects of different traffic conditions on urban road traffic noise have been theoretically compared to each other.

Having calculated the A-weighted sound power level and A-weighted sound pressure level received at the receiver from each and every vehicle, the single event sound exposure level (a constant sound level which has the same amount of energy in 1 second as the original noise level) of the vehicles is calculated as follows:

$$
L_{A E}=10 \log \left(\frac{1}{T_{0}} \sum_{i} 10^{L_{A, i} / 10} . \Delta t_{i}\right)
$$

where

$T_{0}$ is $1 \mathrm{~s}$ (the reference time)

$L_{A, i}$ is A-weighted sound pressure level in the $i^{\text {th }}$ section $(\mathrm{dB}(\mathrm{A}))$

$\Delta t_{i}$ is the time when the sound source exists in the $i^{\text {th }}$ section (s)

The calculated sound exposure level of the entire traffic flow in each traffic condition is summed up according to [28], in order to calculate the total theoretical sound energy emitted from the traffic flow in each traffic condition. Since the point source has been considered to be fixed in the current study, choosing the sound exposure level parameter would help to (to a certain extent) overcome the overestimation of energy. This is due to the fact that we consider the energy in 1 second, with little variations. In general, considering the sound exposure level for calculating the total sound energy is more preferred for the situations we are facing the transient noise (e.g., an aircraft fly-over or a vehicle drive-by). These situations often result in wide variations from background noise to maximum level and if only the maximum level is reported, information on the duration of the noise (an important feature for rating annoyance) is lost. This also makes it difficult to compare between rapid and slow events and to combine different events for noise prediction purposes [43]. It should be highlighted that sound exposure level is numerically equivalent to the total sound energy.

\section{Results and Discussion}

Table 2 shows the theoretical upper and lower boundaries of the emitted noise (sound power level $\left.(\mathrm{dB}(\mathrm{A})), L_{W A}\right)$ and its propagation (sound pressure level $\left.(\mathrm{dB}(\mathrm{A})), L_{A}\right)$ considering $20(\mathrm{~m})$ distance from the source position in each traffic condition. Having estimated the noise emitted by running vehicles in different traffic conditions, $L_{W A}(d B(A))$, the noise level at receiver considering $20(\mathrm{~m})$ distance, $L_{A}(d B(A))$, is calculated based on (6). The theoretical relationship between speed ranges and sound pressure level in different traffic conditions were compared to each other in Figure 4 considering the same number of vehicles (1600 vehicles) in each scenario. By taking a wide look at Figure 4, one can simply find out that the vehicles in free flow condition have emitted sound pressure level in higher ranges compared to the other traffic conditions. It seems to be logical since the range of traffic speed in free flow condition is the highest among the other conditions $(35(\mathrm{~km} / \mathrm{h})$ to $55(\mathrm{~km} / \mathrm{h}))$ based on Table 1 . Also, taking the decelerated traffic flow into account, it is clear that the vehicles emitted sound pressure in a wider range compared to the other traffic conditions. It should be highlighted that, considering the speed-sound pressure level relationship of decelerated flow in Figure 4, the vehicles with the speeds lower than $10(\mathrm{~km} / \mathrm{h})$ have emitted the same sound pressure level as the vehicles with the speed of $10(\mathrm{~km} / \mathrm{h})$. This is due to the fact that, in deceleration running condition, the sound power level at speed of $10(\mathrm{~km} / \mathrm{h})$ is applied at speeds of less than $10(\mathrm{~km} / \mathrm{h})$ according to [28].

Figure 4 suggests the need for considering the dynamics of traffic flow in economic investigations of traffic/transportation policies. For instance, although the vehicles in free flow condition would have the higher sound pressure level compared to the other traffic conditions, they would pass the roadway faster than the vehicles in congestion or any other traffic conditions defined in Figure 1. Therefore, the overall generated single event sound exposure level in different traffic conditions has been considered for a theoretical comparison platform. Since the vehicles in decelerated traffic flow emitted sound pressure in a wider range compared to the 


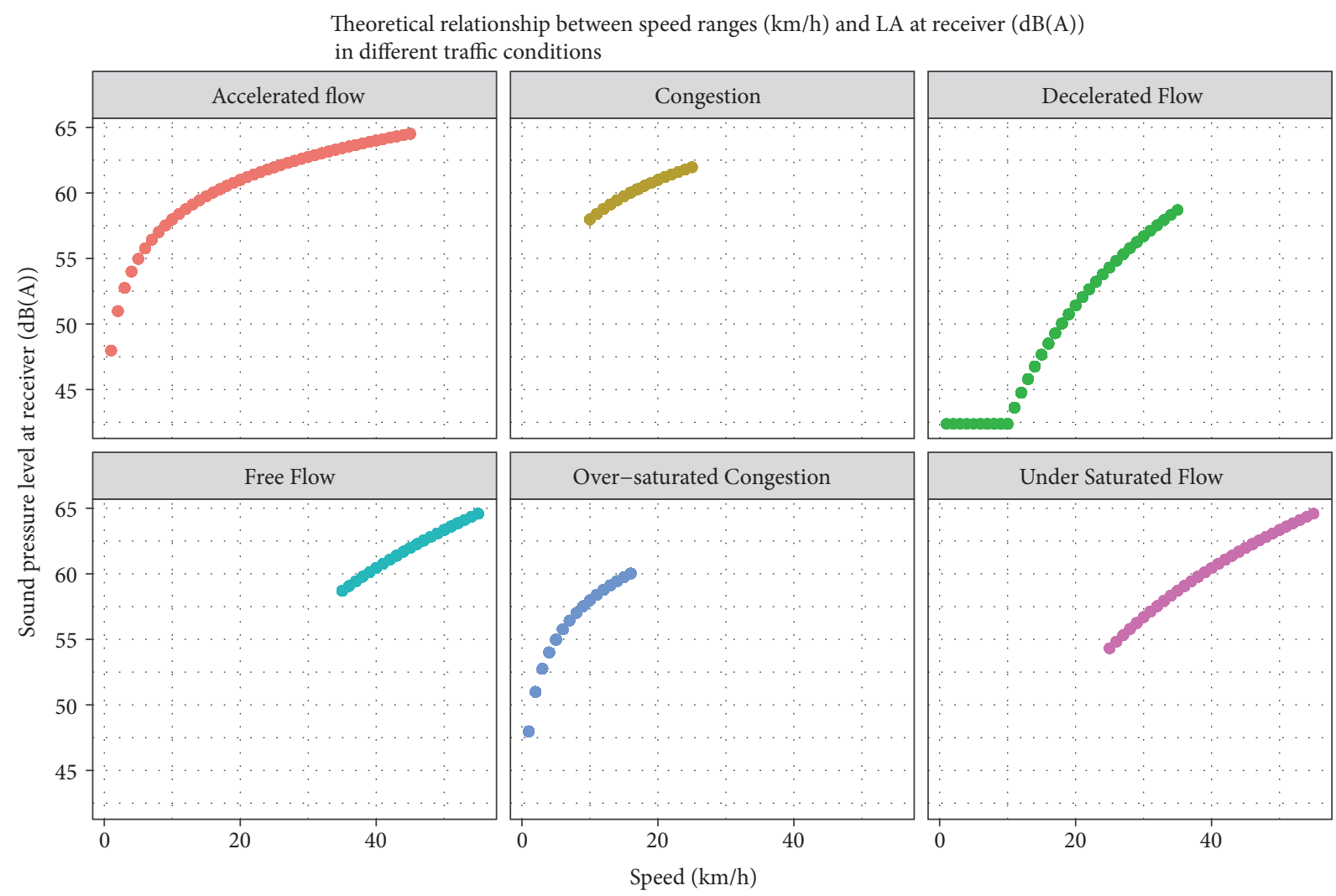

FIGURE 4: Theoretical relationship between speed ranges and the generated sound pressure in different traffic conditions.

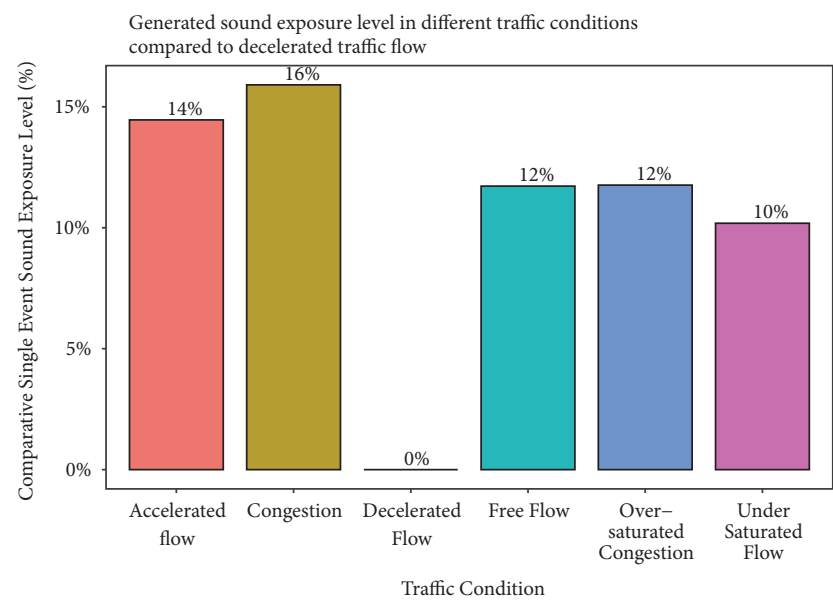

FIGURE 5: Comparing generated single event sound exposure levels in different traffic conditions.

other traffic conditions, the generated sound exposure level in each traffic condition has been compared to the generated sound exposure level in decelerated traffic flow in Figure 5.

Figure 5 clearly shows the fact that the vehicles in decelerated traffic flow would generate considerably lower sound energy compared to the other traffic conditions. Furthermore, comparing Figures 4 and 5 implies the fact that the dynamics of traffic flow which would generate different traffic conditions are of great importance in road traffic noise assessment. For example, although the free flow condition had the highest range of emitted sound pressure level, it has a lower sound exposure level compared to congestion and accelerated flow. Taking (13) into account, one would clearly understand that, apart from the emitted sound pressure level $\left(L_{A}\right)$, the time when sound source exists in the roadway is of great importance in sound energy (sound exposure level) calculations. Therefore, compared to decelerated flow, traffic congestion, accelerated traffic flow, free flow, and undersaturated flow would theoretically generate more sound energy by $16 \%, 14 \%, 12 \%$, and $10 \%$, respectively.

It should be noted that the generated sound energy in decelerated flow condition is lower by $12 \%$ even compared to oversaturated congestion where cars have lower speed range $(1(\mathrm{~km} / \mathrm{h})$ to $15.5(\mathrm{~km} / \mathrm{h}))$ compared to decelerated flow (1 $(\mathrm{km} / \mathrm{h})$ to $35(\mathrm{~km} / \mathrm{h}))$ according to Table 1 . This result might also confirm the suggestion of not just considering the speed ranges in different traffic conditions but also the dynamic nature of the traffic flow might have a considerable impact on the generated sound energy in traffic flow.

According to WHO, continuous exposure to unacceptable noise levels can create the adverse effects on health [8]. Moreover, the research evidence shows that the physiological effect of transportation noise on human sleep may depend more on the level and number of noise events in traffic streams than on energy equivalent measures [44, 45]. Therefore, not just the generated sound energy in road traffic is of great importance but also the distribution (continuity) of road traffic noise would be important. Hence, apart from the 


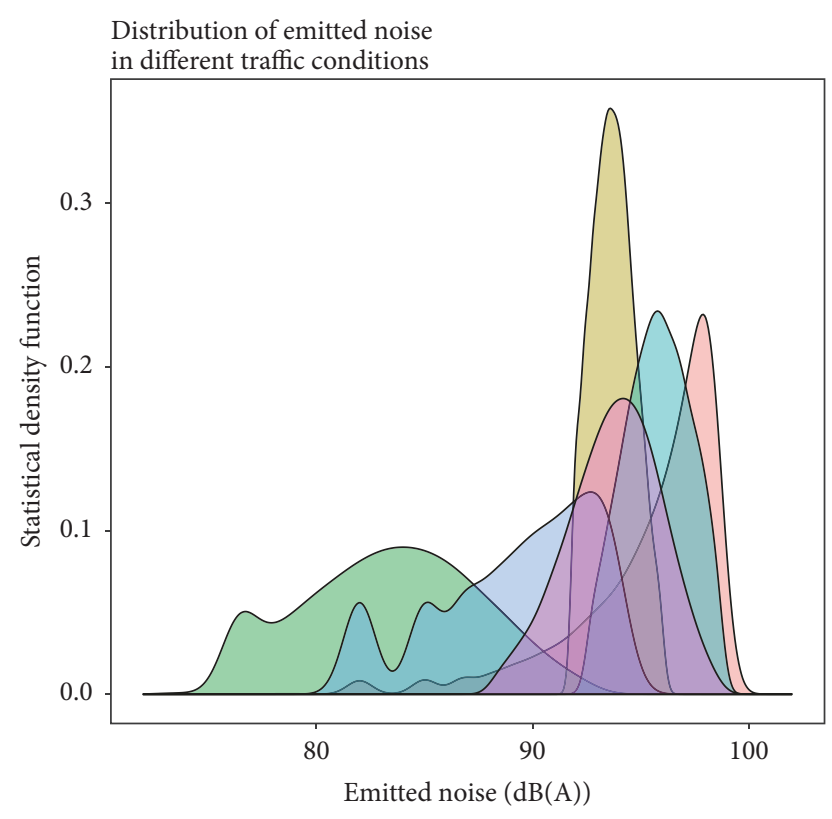

Traffic Condition

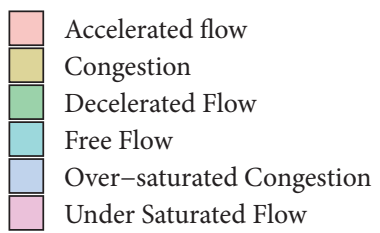

FIGURE 6: Comparing the distributions of emitted noise in different traffic conditions.

comparison of road traffic noise in different traffic conditions in terms of generated sound energy (Figure 5), they were compared in terms of continuity of road traffic noise by the means of density plots as shown in Figures 6 and 7, respectively. Most of the researches in this field suggested that by decreasing the speed rate the road traffic noise will be decreased. For instance, Ellebjerg proposed that noise abatement can be obtained through speed reduction [46]; furthermore Robertson et al. said that traffic calming policy ensures noise reduction since it forbids strong accelerations [47]. In fact, these statements are both true in terms of the generated sound pressure level such that the vehicles with the lower speeds would generate lower sound pressure level (see Figure 4 for illustration).

But the other parameter that needs to be considered in the evaluations is the number of noise events that are exceeded from the maximum thresholds since the physiological effect of transportation noise on human sleep may depend more on the level and number of noise events in traffic streams than on energy equivalent measures $[44,45]$. Based on the abovementioned and considering Figures 6 and 7 which would clearly show the importance of the range of $L_{W A}$ and $L_{A}$, it is evident that different traffic conditions, even with the same generated sound exposure level, might have different effects on their ambience. For instance, comparing Figures 5 and 7 implies the fact that the free flow condition and the oversaturated condition would generate the same amount of

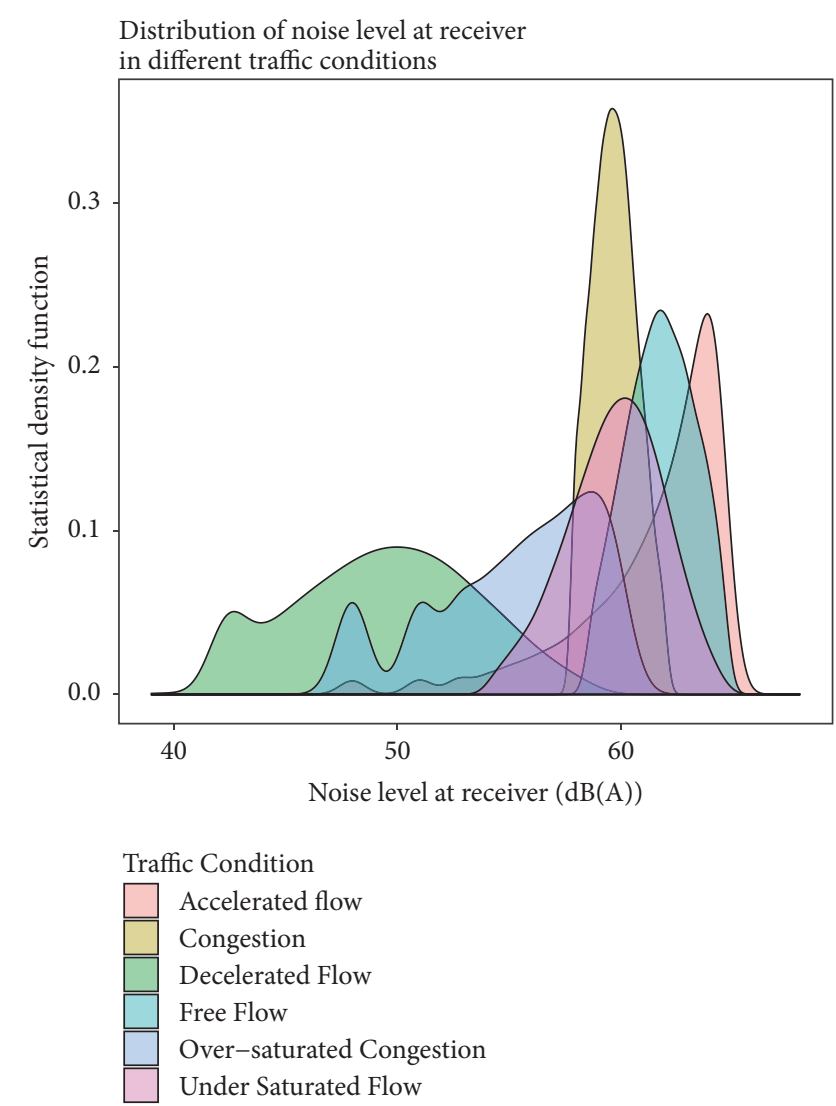

FIGURE 7: Comparing the distributions of noise level at receiver in different traffic conditions.

sound energy (sound exposure level) but the vehicles in free flow condition produce higher range of sound pressure level $(58.7(\mathrm{~dB}(\mathrm{~A}))$ to $64.59(\mathrm{~dB}(\mathrm{~A})))$ compared to oversaturated congestion that ranges from $47.97(\mathrm{~dB}(\mathrm{~A}))$ to $60.02(\mathrm{~dB}(\mathrm{~A}))$. Moreover, Figures 6 and 7 show that the variations of the generated noise in congestion are the lowest compared to the other condition. Also, taking the traffic congestion into account, one would find out that it has, by far, the highest peak in both Figures 6 and 7. This is exactly due to the fact that the range of $L_{W A}$ and $L_{A}$ in traffic congestion (92 $(\mathrm{dB}(\mathrm{A}))$ to $95.97(\mathrm{~dB}(\mathrm{~A}))$ and $57.97(\mathrm{~dB}(\mathrm{~A}))$ to $61.95(\mathrm{~dB}(\mathrm{~A})))$ is shorter than the others based on Table 2. Therefore, the density plots would suggest paying attention to not just the maximum possible road traffic noise which may be caused by vehicle characteristics (speed, acceleration, etc.), but also the possible range of traffic noise which may be caused by nature of traffic condition in evaluation of the consequence of urban road traffic policies.

\section{Conclusions}

The rapid urbanization throughout the world extends the noise pollution, especially those induced by road traffic in the urban districts. Environmental noise exposure is associated with annoyance [9, 10], sleep disturbance [11], cognitive ability in schoolchildren [12], and health impacts, especially cardiovascular conditions [13]. In order to tackle these issues 
caused by road traffic, different traffic and transportation policies might be applied that would generate different traffic conditions. Hence, the effects of different traffic conditions on urban road traffic noise have been theoretically compared in this paper. The results show that when the traffic flow is in deceleration process it would theoretically generate lower sound energy compared to congestion, accelerated flow, free flow, and undersaturated flow by $16 \%, 14 \%, 12 \%$, and $10 \%$, respectively (see Figure 5). It should be noted that the generated sound energy in decelerated flow condition is lower by $12 \%$ even compared to oversaturated congestion where cars have lower speed range $(1(\mathrm{~km} / \mathrm{h})$ to $15.5(\mathrm{~km} / \mathrm{h}))$ compared to decelerated flow $(1(\mathrm{~km} / \mathrm{h})$ to $35(\mathrm{~km} / \mathrm{h}))$ according to Table 1. Furthermore, by taking a wide look at Figure 5, one would find out that free flow and oversaturated congestion would theoretically generate equal sound energy (sound exposure level) whereas they have different traffic speed ranges according to Table 1 . In fact, these results would suggest that the emitted road traffic noise is the production of both traffic speed and dynamic nature of the traffic flow (pay attention to the range of the traffic noise in Table 2). Most of the researches in this field suggested that by decreasing the speed rate the road traffic noise will be decreased. For instance, Ellebjerg proposed that noise abatement can be obtained through speed reduction [46]; furthermore Robertson et al. said that traffic calming policy ensures noise reduction since it forbids strong accelerations [47].

Based on the abovementioned and considering Figures 6 and 7 which would clearly show the importance of the range of $L_{W A}$ and $L_{A}$, it is evident that different traffic conditions, even with the same generated sound exposure level, might have different effects on their ambience. For instance, comparing Figures 5 and 7 implies the fact that the free flow condition and the oversaturated condition would generate the same amount of sound energy (sound exposure level) but the vehicles in free flow condition produce higher range of sound pressure level $(58.7(\mathrm{~dB}(\mathrm{~A}))$ to $64.59(\mathrm{~dB}(\mathrm{~A})))$ compared to oversaturated congestion that ranges from 47.97 $(\mathrm{dB}(\mathrm{A}))$ to $60.02(\mathrm{~dB}(\mathrm{~A}))$. Moreover, Figures 6 and 7 show that the variation of the generated noise in congestion is the lowest compared to the other condition. Lastly, comparing the generated noises in different traffic conditions by density plots revealed the fact that not only is the generated sound exposure level in road traffic noise important but also the range of the generated noise in different traffic conditions is of significant importance. In this paper, the results showed that different traffic conditions might theoretically generate the same amount of noise (considering the equal number of vehicles) but in different ranges. Therefore, it might be concluded that the traffic condition that would generate the noise in the higher ranges (considering the distribution of generated noise in different traffic conditions) might have more negative effect on its ambience compared to the one that generates noise in lower ranges.

In the end, it should be highlighted that this research attempts to study neither the influence of junctions nor the influence of different driving patterns on noise emissions. But instead, it seeks to compare the average influences of different traffic conditions on urban road traffic noise in a theoretical environment. The scope for the future study is to calibrate the range of emitted noise in different traffic conditions in a real practice and build up a comparison environment based on the collected on-site values for further incorporation in the economic investigation of the road traffic policies.

\section{Data Availability}

The data used to support the findings of this study are available from the corresponding author upon request.

\section{Conflicts of Interest}

The authors declare that there are no conflicts of interest regarding the publication of this paper.

\section{Acknowledgments}

The research reported in this paper was supported by the Higher Education Excellence Program of the Ministry of Human Capacities in the frame of Artificial Intelligence research area of Budapest University of Technology and Economics (BME FIKP-MI/FM). Moreover, the authors are grateful for the support of HAS (Hungarian Academy of Science) for providing the János BÓLYAI Scholarship. The first author further gratefully acknowledges the support of Stipendium Hungaricum of Tempus Public Foundation.

\section{References}

[1] J. B. Zavada, B. Abramovic', and Š. Denis, "A strategic model of sustainable mobility in the city of zagreb and its surrounding area," International Journal for Traffic \& Transport Engineering, vol. 7, no. 4, 2017.

[2] I. Ivković, O. Čokorilo, and S. Kaplanović, “The estimation of GHG emission costs in road and air transport sector: Case study of Serbia," Transport, vol. 33, no. 1, pp. 260-267, 2018.

[3] K. Jadaan, H. Khreis, and Á. Török, "Exposure to traffic-related air pollution and the onset of childhood asthma: a review of the literature and the assement methods used," Periodica Polytechnica Transportation Engineering, vol. 46, no. 1, p. 21, 2017.

[4] B. S.-O. S.-C. Li, "The issues of measuring the exterior and interior noise of road vehicles," Energy Intensity and GHG Production of Chosen Propulsions Used in Road Transport, vol. 19, p. 50, 2017.

[5] B. Abramović, "Infrastructure access charges," in Sustainable Rail Transport, Lecture Notes in Mobility, pp. 45-58, Springer International Publishing, Cham, 2018.

[6] C. Guarnaccia, "Advanced tools for traffic noise modelling and prediction," WSEAS Transactions on Systems, vol. 12, no. 2, pp. 121-130, 2013.

[7] I. Varga, "A congestion detection based traffic control for signalized intersection," Periodica Polytechnica Civil Engineering, vol. 62, no. 2, p. 398, 2015.

[8] WHO, "Night noise guidelines for Europe," World Health Organization-Regional Office for Europe, 2009. 
[9] W. Babisch, G. Pershagen, J. Selander et al., "Noise annoyance - A modifier of the association between noise level and cardiovascular health?" Science of the Total Environment, vol. 452-453, pp. 50-57, 2013.

[10] C. Clark, R. Crombie, J. Head, I. Van Kamp, E. Van Kempen, and S. A. Stansfeld, "Does traffic-related air pollution explain associations of aircraft and road traffic noise exposure on children's health and cognition? A secondary analysis of the United Kingdom sample from the RANCH project," American Journal of Epidemiology, vol. 176, no. 4, pp. 327-337, 2012.

[11] WHO-JRC, "Burden of disease from environmental noise: Quantification of healthy life years lost in Europe," OCLC: 779684347, 2011.

[12] C. Clark, J. Head, and S. A. Stansfeld, "Longitudinal effects of aircraft noise exposure on children's health and cognition: A six-year follow-up of the UK RANCH cohort," Journal of Environmental Psychology, vol. 35, pp. 1-9, 2013.

[13] A. L. Hansell, M. Blangiardo, L. Fortunato et al., "Aircraft noise and cardiovascular disease near Heathrow airport in London: Small area study," BMJ, vol. 347, no. 7928, 2013.

[14] M. S. Hammer, T. K. Swinburn, and R. L. Neitzel, "Environmental noise pollution in the United States: Developing an effective public health response," Environmental Health Perspectives, vol. 122, no. 2, pp. 115-119, 2014.

[15] P. Pamanikabud and P. Vivitjinda, "Noise prediction for highways in Thailand," Transportation Research Part D: Transport and Environment, vol. 7, no. 6, pp. 441-449, 2002.

[16] J. Gulliver, D. Morley, D. Vienneau et al., "Development of an open-source road traffic noise model for exposure assessment," Environmental Modeling and Software, vol. 74, pp. 183-193, 2015.

[17] World Health Organization, "Prevention of noise-induced hearing loss," Report of a WHO-PDH Informal Consultation, Geneva, 1997.

[18] M. M. Zefreh, F. Meszaros, R. Junevičius, and A. Torok, "Economic investigation of a public transport support policy: a case study at Budapest," Promet-Traffic \& Transportation, vol. 29, no. 1, pp. 77-84, 2017.

[19] N. Garg and S. Maji, "A critical review of principal traffic noise models: strategies and implications," Environmental Impact Assessment Review, vol. 46, pp. 68-81, 2014.

[20] L. Ellebjerg and H. Bendtsen, "Possibilities of noise reduction through road traffic flow management," in Proceedings of the INTER-NOISE and NOISE-CON Congress and Conference Proceedings, pp. 2601-2609, 2007.

[21] H. Bendtsen, J. Haberl, U. Sandberg, G. Watts, and E. Pucher, Traffic Management and Noise Reducing Pavements-Recommendations on Additional Noise Reducing Measures (Silvia, Sustainable Road Surfaces for Traffic Noise Control), Roskilde, Denmark, 2005.

[22] A. Rust, J. Affenzeller, and J. Hinton, "Plans for future european research to reduce transport noise," in Proceedings of the INTERNOISE and NOISE-CON Congress and Conference Proceedings, pp. 2048-2057, Institute of Noise Control Engineering, 2007.

[23] V. Desarnaulds, M. Gilbert, and A. Carvalho, "Noise reduction by urban traffic management," in Proceedings of the ICA, 2004.

[24] A. Can and P. Aumond, "Estimation of road traffic noise emissions: The influence of speed and acceleration," Transportation Research Part D: Transport and Environment, vol. 58, pp. 155171, 2018.

[25] M. T. Barry and A. J. Reagan, "Fhwa highway traffic noise prediction model,” Tech. Rep., 1978.
[26] UK Department of Transport, Calculation of Road Traffic Noise, 1988.

[27] G. Watts, "Harmonoise models for predicting road traffic noise," Acoustics Bulletin, vol. 30, no. 5, pp. 19-25, 2005.

[28] S. Sakamoto, "Road traffic noise prediction model "ASJ RTNModel 2013": Report of the Research Committee on Road Traffic Noise," Acoustical Science and Technology, vol. 36, no. 2, pp. 49108, 2015.

[29] A. Török and M. M. Zefreh, "Assessing the Need for Applying Multimodal Speed Distribution in Road Transport Macro Emission Estimation," Acta Technica Jaurinensis, vol. 9, no. 2, pp. 118-127, 2016.

[30] G. Watts, D. van Maercke, H. van Leeuwen et al., "Effects of speed distributions on the harmonnoise model predictions," in Proceedings of the INTER-NOISE and NOISE-CON Congress and Conference Proceedings, vol. volume, pp. 2530-2536, Institute of Noise Control Engineering, 2004.

[31] G. Iannone, C. Guarnaccia, and J. Quartieri, "Speed distribution influence in road traffic noise prediction," Environmental Engineering and Management Journal, vol. 12, no. 3, pp. 493-501, 2013.

[32] F. Li, Y. Lin, M. Cai, and C. Du, "Dynamic simulation and characteristics analysis of traffic noise at roundabout and signalized intersections," Applied Acoustics, vol. 121, pp. 14-24, 2017.

[33] L. Estévez-Mauriz and J. Forssén, "Dynamic traffic noise assessment tool: A comparative study between a roundabout and a signalised intersection," Applied Acoustics, vol. 130, pp. 71-86, 2018.

[34] P. P. Dey, S. Chandra, and S. Gangopadhaya, "Speed distribution curves under mixed traffic conditions," Journal of Transportation Engineering, vol. 132, no. 6, pp. 475-481, 2006.

[35] H. J. Leong, "The distribution and trend of free speeds on two lane two way rural highways in new south wales," in Proceeding of the 4th Australian Road Research Board (ARRB) Conference, vol. 4, 1968.

[36] McLean. J. r., "Observed speed distributions and rural road traffic operations," in Proceedings of the Australian Road Research Board Conference, vol. 9, 1979.

[37] C. Minh, K. Sano, and S. Matsumoto, "Characteristics of passing and paired riding maneuvers of motorcycle," Journal of the Eastern Asia Society for Transportation Studies, vol. 6, pp. 186197, 2005.

[38] Y. Wang, W. Dong, L. Zhang et al., "Speed modeling and travel time estimation based on truncated normal and lognormal distributions," Transportation Research Record, no. 2315, pp. 6672, 2012.

[39] D. L. Georlough and M. J. Huber, "Traffic flow theory: A monograph, special report 165," Transportation Research Board, 1975.

[40] A. F. Haight and W. W. Mosher, "A practical method for improving the accuracy of vehicular speed distribution measurements," Highway Research Board Bulletin, vol. 341, pp. 92-116, 1962.

[41] M. Elhenawy, H. Rakha, and H. Chen, "An automatic traffic congestion identification algorithm based on mixture of linear regressions," in Smart Cities, Green Technologies, and Intelligent Transport Systems, vol. 738 of Communications in Computer and Information Science, pp. 242-256, Springer International Publishing, Cham, 2017.

[42] M. Elhenawy, H. Rakha, and H. Chen, "A unified real-time automatic congestion identification model considering weather 
and roadway visibility conditions," in Proceedings of the 2nd International Conference on Vehicle Technology and Intelligent Transport Systems, VEHITS 2016, pp. 39-48, Italy, April 2016.

[43] P. Bernard, Leq, SEL: When? Why? How? Brüel \& Kjær, 1975.

[44] B. Griefahn, A. Marks, and S. Robens, "Noise emitted from road, rail and air traffic and their effects on sleep," Journal of Sound and Vibration, vol. 295, no. 1-2, pp. 129-140, 2006.

[45] S. Pirrera, E. De Valck, and R. Cluydts, "Nocturnal road traffic noise: A review on its assessment and consequences on sleep and health," Environment International, vol. 36, no. 5, pp. 492$498,2010$.

[46] L. Ellebjerg, "Effectiveness and benefits of traffic flow measures on noise control," Deliverable H. D, vol. 1, 2007.

[47] S. Robertson, W. Heather, and G. Marsden, Ulf Sandberg, and Ulf Hammerstrom. The effects of speed on noise, vibration and emissions from vehicles [Master, thesis], Public Master, 1998. 


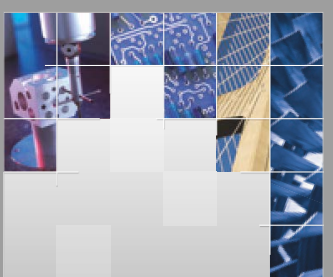

\section{Enfincering}
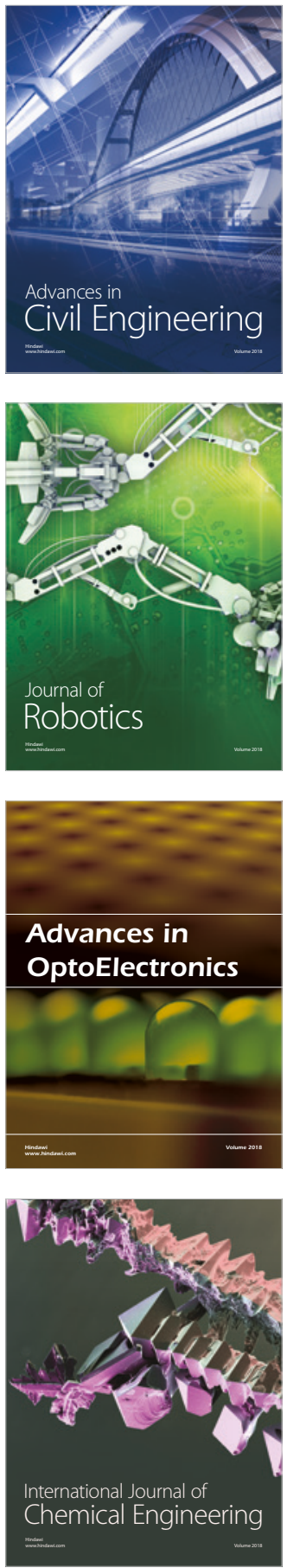

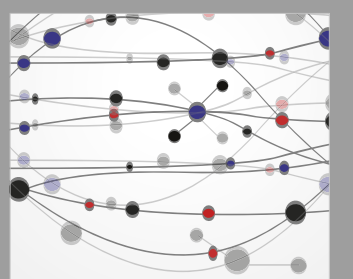

\section{Rotating \\ Machinery}

The Scientific World Journal

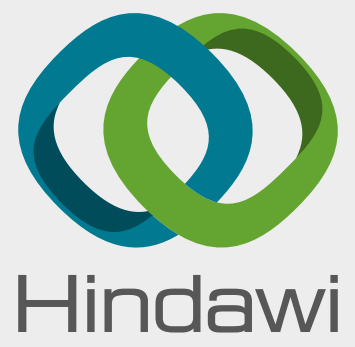

Submit your manuscripts at

www.hindawi.com
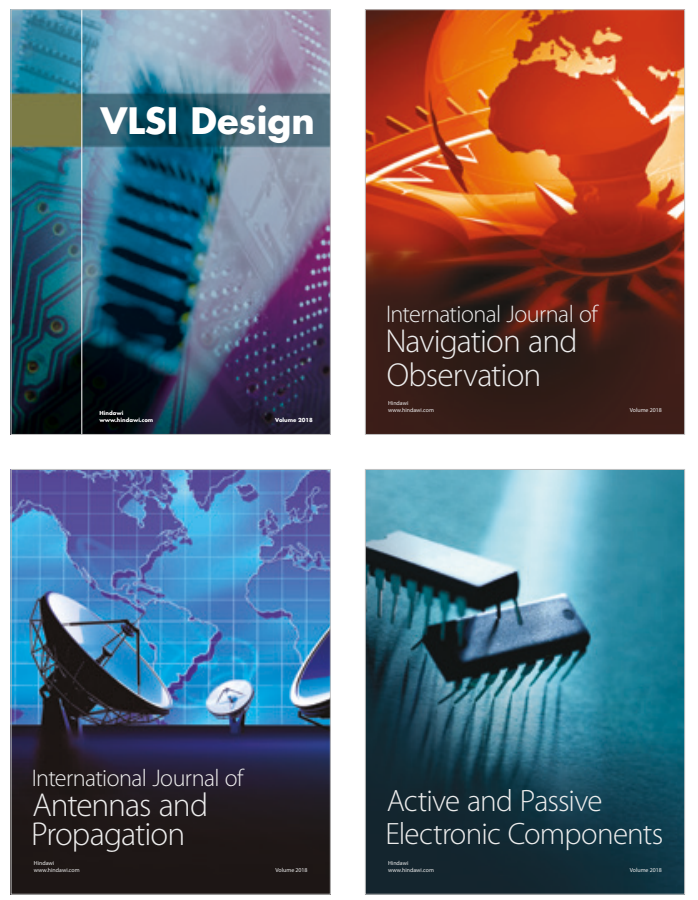
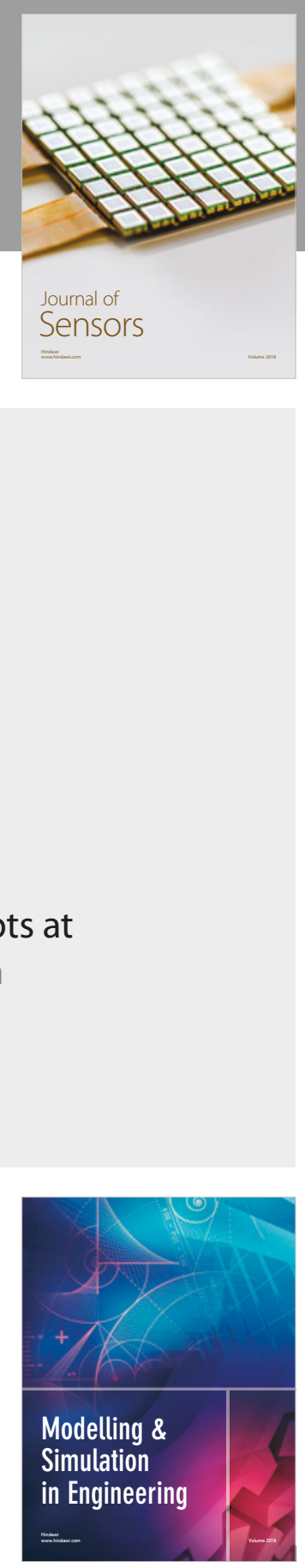

\section{Advances \\ Multimedia}
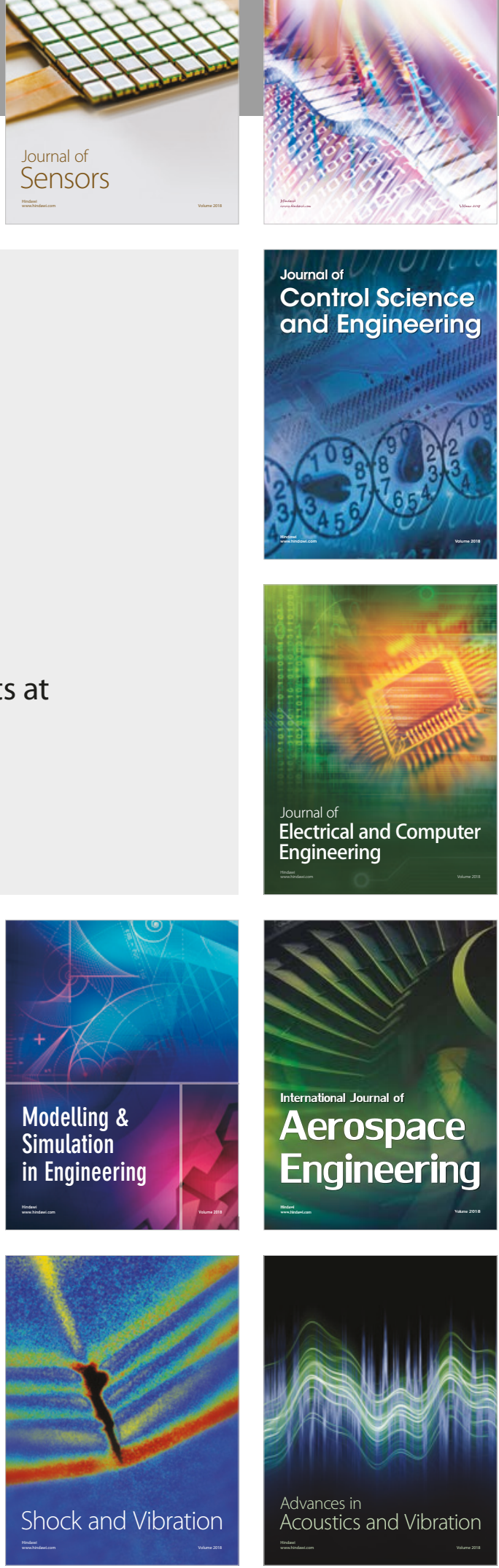